\title{
Cardiovascular Health Delivery System in Belarus Contrasted to the United States
}

Inna Porter, M.D.

\author{
James L. Vacek, M.D., F.A.C.P., F.A.C.C., F.A.H.A.
}

University of Kansas Hospital, Kansas City, KS

\section{Introduction}

Health service and resource availability and utilization vary markedly between nations. We contrasted cardiovascular care and technology in Belarus and the United States. One author (Dr. Inna Porter) was a practicing cardiologist in Belarus until 2002.

Belarus is one of the countries of the former Soviet Union which achieved independent status in 1991. It is located in the center of Europe and shares borders with Russia, Ukraine, Poland, Lithuania, and Latvia. Belarus with a territory of 208,000 square kilometers is about the same size as the state of Kansas. With a population of 10.3 million, Belarus has about the same number of citizens as the state of Ohio and about four times more citizens than the state of Kansas.

Minsk is the capital of Belarus and is home to approximately $15 \%$ of the population. Over $80 \%$ of the population is Belarusian, $10 \%$ are Russians, and the remaining $10 \%$ are mostly Ukrainian and Polish. The Russian Orthodox religion is predominant in Belarus. There are also small populations of Roman Catholics and Jews.

In the first years after the break up of the Soviet Union, there was a profound economic collapse in Belarus that affected the health system and the health of the population in general. The Chernobyl disaster on the border of neighboring Ukraine also had a direct impact on the health of the people. Life expectancy in Belarus in 2003 was 62.7 years for males and 74.7 years for women. ${ }^{1}$ In comparison, life expectancy in the United States in 2002 was 74.5 years for males and 79.9 for females. ${ }^{2}$ Cardiovascular disease and cancer are the leading causes of death in both countries. Although medical care now is much improved in Belarus, it still remains inadequate compared to the delivery of health care in most European countries and the United States.

\section{Brief Overview of Belarusian Health Care Delivery System and Its Structure ${ }^{3}$}

The delivery of health care, its structure, and organization in Belarus have not evolved much since the declaration of independence. There is free access to health care for all citizens of Belarus that is financed by the government. Regardless of socioeconomic status, everyone is eligible for a comprehensive package of free health care benefits. This package includes all care offered by most state institutions except prescribed outpatient medications, glasses, cosmetic surgery, and some dental services.

There are additional ways to obtain medical services in Belarus. Patients can choose a private clinic and pay for the services out of their own pocket or they can pay directly to a state institution for services that were not requested by the patient's provider. The other way one can obtain enhanced medical care is to pay for supplemental health insurance. This insurance is offered by private companies and is intended to cover expenses not covered by government provided services.

Each citizen of Belarus is assigned to a local polyclinic. This means that each polyclinic must provide care for all of the people living within a designated territory. The patients who require procedures that are 
not offered locally are referred to a regional clinic or hospital, where more specialized services are available.

Most pharmaceuticals in Belarus can be purchased without prescription. The medications that must be obtained with a prescription are narcotics, medications used in psychiatry, sedatives, tranquilizers, and tinctures with a high percentage of ethanol. Such access to pharmaceuticals leads sometimes to self-treatment, especially in cases of cough, diarrhea, headache, and any kind of pain.

\section{Cardiovascular Care in Belarus}

The system of health care delivery described above works quite well if a patient needs to see a primary care or a specialty doctor, requires general surgical procedures, or needs emergency care. Many changes were made in the past several years to improve medical care in Belarus including building several new fully-equipped hospitals and opening new clinics. Due to economic difficulties, there is a shortage of medical equipment, but most basic procedures are readily available.

Echocardiograms, chemical and exercise stress tests, esophagogastroduodenoscopies, and colonoscopies are available in most of the regional polyclinics and hospitals. Due to the limited availability of magnetic resonance imaging or computed tomography equipment, it is more difficult to get these studies performed and they are not used widely. For the same reason, only one cardiology institution in Belarus offers myocardial perfusion studies. There are only four hospitals in the Republic that offer interventional cardiological procedures.

The availability of heart catheterization and open-heart surgeries has increased in the past few years due to the opening of new cardiology hospitals. There were a total of 1140 coronary angiographies performed in 2004 for the entire population of over ten million people. In comparison, over 50,000 coronary angiographies were performed in the United States per population of over ten million people in 2003. Table 1 contains approximate data of some cardiovascular procedures that were done in Belarus in 2004 and the United States in 2003 per ten million people. ${ }^{4-6}$

The limited availability of interventional cardiology procedures caused by inadequate government funding has led to unspoken rationing when choosing patients for a heart catheterization. The criteria of age, presence of associated severe diseases, untreated alcoholism, or high-risk complications are used when choosing patients for free coronary angiography. A special commission of Health Ministry must approve each free heart catheterization. The age of the selected patients is usually under 65. A patient also can pay the equivalent of $\$ 350$ (US) out of pocket for diagnostic heart catheterization (The median salary in Belarus is about $\$ 150-200$ (US) per month). Angioplasty and stenting also could be performed if the patient pays for them, but the cost of these procedures is unaffordable for most patients.

Coronary angiography and angioplasty often are done for the patient only after recovery following myocardial infarction, but not during the acute stage. Absence of an emergent interventional cardiology program is probably the main reason for delay. There also is belief that the more stable the patient, the better the chance that he or she will survive the procedure and would have fewer complications. The patient's decision also plays a big role in whether to proceed with heart catheterization or not. Many Belarusian patients favor more conservative treatments. Occurrence of severe angina may push them finally to have an interventional procedure. 
Table 1. Cardiovascular procedures done in Belarus in 2004 and the US in 2003 per 10,000,000 people.

\begin{tabular}{|c|c|c|c|c|c|c|}
\hline & $\begin{array}{c}\text { Cardiac } \\
\text { Catheterizations }\end{array}$ & \begin{tabular}{|c|} 
Cardiac \\
Catheterizations \\
With \\
Angioplasty \\
and/or Stenting \\
\end{tabular} & $\begin{array}{c}\text { Bypass } \\
\text { Surgeries }\end{array}$ & $\begin{array}{c}\text { Valve } \\
\text { Replacement } \\
\text { Surgeries }\end{array}$ & $\begin{array}{c}\text { Surgeries For } \\
\text { Congenital } \\
\text { Heart Diseases }\end{array}$ & $\begin{array}{l}\text { Pacemaker } \\
\text { Placement }\end{array}$ \\
\hline Belarus & 1140 & 74 & 674 & 334 & 423 & 1600 \\
\hline USA & 50,000 & 18,622 & 17,859 & 3225 & 867 & 6900 \\
\hline
\end{tabular}

In Belarus, the mortality rate during and after bypass surgery is about $4.6 \%{ }^{4}$ This is higher compared to the rate of $2.4 \%$ in the United States. ${ }^{6}$ Assuming that bypass surgeries are usually done in a lower risk population in Belarus (due to the selection factors noted above), the higher death rate could be related to such factors as inadequate intraoperative and postoperative care due to shortage of nurses, specialized beds, medical supplies, and some medications.

The postoperative mortality rate of valve replacement surgeries is about $4.7 \%$ in Belarus. ${ }^{4}$ This is lower than in the United States where mortality rate after the same procedure is about $5.8 \% .^{6}$ This difference could be related to the selection of a lower risk patient population in Belarus.

Patients with myocardial infarction usually receive standard supportive therapy with beta-blocker, aspirin, angiotensin converting enzyme inhibitor, heparin, and thrombolysis if indicated. Inhibitors of platelet glycoprotein $2 b / 3 a$ receptors almost never are used in Belarus because of the high cost. The statins and anti-platelets like clopidogrel are prescribed widely by doctors. However due to their high cost, most patients cannot afford to buy them.

A cardiac balloon pump is available only in the Republic Cardiology Institute and is not used often due to the cost of its initiation and operation. Patients receive therapy with heparin for about three weeks after an acute event. The average hospital stay after acute myocardial infarction is 14-16 days. After that, patients usually are sent to free rehabilitation centers for 21 more days. Physicians in Belarus are instructed not to discharge the patient unless the most vulnerable period after acute myocardial infarction is over.

The average hospital stay after acute myocardial infarction in the United States is only 3.7 days. These profound differences in post-infarction length of stay may be related to many factors including the use of invasive interventional procedures in the US, the impact of third party insurance and Medicare coverage for hospitalizations, greater impact of evidence-based guidelines in the US, as well as cultural differences between the nations.

About 24 bypass tract ablations a year are performed in the Republic Cardiac Institute. This is the only place where this procedure is performed and patients referred here usually have recurrent arrhythmias due to Wolf-Parkinson-White syndrome. There are only two hospitals in Belarus that offer pacemaker placement. Heart transplant is not available in Belarus.

Lack of interventional procedures in Belarus is probably the main reason why the mortality rate from cardiovascular diseases is much higher than in the US. The hospital mortality of the patients with acute myocardial infarction in Belarus is $8.9 \%$ while in the US it is only $2.5 \%{ }^{4,6}$ 
Interestingly, the mortality rate ratio from coronary heart disease for males and females is similar in both countries: 1.6 to 1 in the US and 1.7 to 1 in Belarus.

Table 2 summarizes the latest available data on mortality from some cardiovascular diseases in the US, Belarus, and countries of the Commonwealth of Independent States (CIS; an organization for economic cooperation composed of several republics of the former Soviet Union) per 100,000 populations in 2003. The mortality from cardiovascular diseases is more than twice as high in Belarus than in the US. In spite of higher mortality rates, the prevalence of cardiovascular diseases and risk factors in Belarus is reported as significantly lower than in the US (Tables 3 and 4), although this may be due in part to less screening and recognition.

In comparison with other CIS countries, the mortality in Belarus is much lower. Belarus is the only country from the former Soviet Union where free medical care still exists and is easily available. This health system may be one of the reasons for the lower mortality rate in Belarus than in other CIS countries.

Table 2. Mortality from cardiovascular diseases in the US, Belarus, and CIS countries per 100,000 people in 2003.

\begin{tabular}{|c|c||c|c|}
\hline Country & Cardiovascular Diseases & Coronary Heart Diseases & Cerebrovascular Diseases \\
\hline US & 309 & 163 & 56 \\
\hline \hline Belarus & 694 & 456 & 173 \\
& 821 & 434 & 251 \\
\hline \hline CIS countries & & & \\
\hline
\end{tabular}

Table 3. Prevalence of cardiovascular diseases in the US and Belarus per 100,000 adult populations.

\begin{tabular}{|c||c|c|c|c|}
\hline Country & $\begin{array}{c}\text { Cardiovascular } \\
\text { Diseases }\end{array}$ & $\begin{array}{c}\text { Coronary Heart } \\
\text { Diseases }\end{array}$ & $\begin{array}{c}\text { Myocardial } \\
\text { Infarction }\end{array}$ & Angina Pectoris \\
\hline \hline US (2003) & 32,750 & 6062 & 397 & 3903 \\
\hline \hline Belarus (2003) & 26,911 & 8169 & 169 & 2226 \\
\hline \hline
\end{tabular}

Table 4. Prevalence of coronary artery disease risk factors in the US and Belarus.

\begin{tabular}{|c|c||c|c||c||c||c|}
\hline \hline Country & Hypertension & $\begin{array}{c}\text { Diabetes } \\
\text { Mellitus }\end{array}$ & Tobacco & Hypercholesterolemia & $\begin{array}{c}\text { Physical } \\
\text { Inactivity }\end{array}$ & $\begin{array}{c}\text { Overweight/ } \\
\text { Obese }\end{array}$ \\
\hline \hline $\begin{array}{c}\text { US } \\
(2003)\end{array}$ & $32 \%$ & $7 \%$ & $21 \%$ & $50 \%$ & $61 \%$ & $65 \%$ \\
\hline \hline Belarus & $\begin{array}{c}15 \% \\
(2003)^{4}\end{array}$ & $\begin{array}{c}2 \% \\
(2003)^{1}\end{array}$ & $\begin{array}{c}27 \% \\
(2003) 1\end{array}$ & $\begin{array}{c}36 \% \\
(1999)^{7}\end{array}$ & $\begin{array}{c}17 \% \\
(1999)^{7}\end{array}$ & $\begin{array}{c}24 \% \\
(1999)^{7}\end{array}$ \\
\hline \hline
\end{tabular}


A lower prevalence of cardiovascular diseases in Belarus may be related in part to a high mortality rate and a shorter life span compared to the US, in addition to the reporting factors mentioned above. While the accuracy of Belarusian statistical data may account to some degree for the lower prevalence of risk factors, other reasons, such as physical activity and a healthier diet, may contribute to the lower prevalence of risk factors. Belarusian people probably have a more physically active lifestyle than Americans. For example, only about 22\% of Belarusian people own a car. Although use of public transportation is common, walking to the places of work or shopping are more typical for Belarusians than for Americans.

It is customary for people in Belarus who live in suburban or urban areas to own a country house, called a "dacha", with a small parcel of land, where people grow vegetables and fruits during spring to fall. City dwellers usually go there on weekends to work on their garden. The garden work involves a lot of physical activity as most is done by hand without any heavy machinery. The produce from the dachas are for personal consumption and rarely sold on the market. Some of the vegetables and fruits are preserved for use during the winter. While no reliable studies have been done in Belarus to evaluate the diet structure, it is more likely that the diet intake of Belarusians is higher in fiber and lower in saturated fats, sugar, and salt, than the diet of Americans.

As shown in Table 4, smoking is more prevalent in Belarus than in the US. According to the surveys, $68 \%$ to $83 \%$ of all smokers in Belarus are males. ${ }^{8,9}$ In the US, the percent of smoking males and females is about the same. High tobacco use among Belarusian males could contribute to their shorter lifetime compare to the Belarusian women.
Preventive cardiovascular medicine in Belarus and in the US is somewhat different. People in Belarus are educated about cardiovascular risk factors and a healthy lifestyle through the mass media, brochures, and lectures that are given in polyclinics. Educational lectures also are held periodically for employees of different factories, schools, and institutions. Education is focused more on a healthy lifestyle rather than on taking lipid-lowering medications.

Lipid profile screening tests are offered at no cost in most polyclinics. Recreation centers are common in big cities, but not in most small towns. Use of statins is significantly lower in Belarus than in the US, but use of herbal medicine and fish oil is very popular. Preventive medicine in the US as contrasted to that in Belaurus may differ in regards to attention to a healthy lifestyle as opposed to pharmacologic intervention, but detailed information regarding these factors is not available. While preventive medicine exists in both countries, the relative effectiveness in prevention of cardiovascular diseases at this point remains unclear.

\section{Summary}

Despite the economic crisis that Belarus has experienced after the collapse of the Soviet Union, the Belarusian government has managed to provide a free comprehensive package of heath care to the entire population. Remarkable achievements have been made in providing unlimited access to free services, but lack of available resources and funding remains a significant problem for optimal care. Thus, due to limited finances and a shortage of medical equipment, procedures like heart catheterization and open-heart surgery are available mostly to a selected younger group of patients. Most sophisticated medical services are not readily available in the rural 
areas. All these factors lead to a higher mortality rate from cardiovascular diseases. An increased number of interventional procedures may lower the mortality rate, but lack of funding may impede further development of cardiovascular care in Belarus for many years. In this situation, development of an alternative insurance subsidized care plan would be a very important factor in providing the best treatment for cardiac patients.

Although medical care in Belarus lags behind most Western European countries and the US, it is more easily accessible com-

\section{References}

${ }^{1}$ World Health Organization (WHO). European health for all database (HFADB). Belarus Country Report. [http://www.euro.who.int/hfadb]. Accessed: 01/06/2006.

${ }^{2}$ Hoyert DL, Kung HC, Smith BL. Deaths: Preliminary data for 2003. Natl Vital Stat Rep 2005; 53:1-48.

${ }^{3}$ World Health Organization (WHO). European observatory on health care systems. Health care systems in transition: Belarus.

[http://www.euro.who.int/document/e7244 8.pdf]. Accessed: 01/06/2006.

${ }^{4}$ Public Health Ministry of the Republic of Belarus: Division of Methodology And Analysis of Medical Statistics. Public Health in the Republic of Belarus. An Official Statistics Collection. Minsk: GU RNMB, 2004.

5 Ostrovski YP. Highlights and perspectives of cardiovascular surgery in Belarus. [http://www.doctors.artamedica.com]. Accessed: 07/18/2005.

${ }^{6}$ American Heart Association. Heart Disease and Stroke Statistics-2006 Update. Dallas: American Heart Association, 2004. pared to other countries of the former Soviet Union. According to the survey of Balabanova and colleagues $^{10}, 9.4 \%$ of Belarusian people did not seek professional care when they experienced an episode of illness. Only $0.7 \%$ of those respondents reported that the reason for not seeking care was lack of money. These numbers were significantly lower than in the other former Soviet Union countries that underwent a similar survey. While the health care in Belarus is affordable and easily accessible, there is still concern about its sustainability in the face of economic problems.

${ }^{7}$ World Health Organization (WHO). Highlights on health in Belarus. [http://www.euro.who.int/document/e7201 6.pdf]. Accessed: 01/06/2006.

${ }^{8}$ Gilmore AB, McKee M, Rose R. Prevalence and determinants of smoking in Belarus: A national household survey. Euro J of Epidemiol 2001; 17:245-253.

${ }^{9}$ Gilmore A, Pomerleau J, McKee M, et al. Prevalence of smoking in eight countries of the former Soviet Union: Results from the living conditions, lifestyles, and health study. Am J Public Health 2004; 94:21772187.

${ }^{10}$ Balabanova D, McKee M, Pomerleau J, Rose R, Haerpfer C. Health service utilization in the former Soviet Union: Evidence from eight countries. Health Serv Res 2004; 39(6 Pt 2):19271950.

Keywords: delivery of health care, Belarus, cardiovascular system, United States 